\title{
Sampling Schemes by Variables Inspection for the First-Order Autoregressive Model between Linear Profiles
}

\author{
Yeneneh Tamirat, ${ }^{1}$ Fu-Kwun Wang, ${ }^{2}$ and Yen-Chih Chen ${ }^{3}$ \\ ${ }^{1}$ Department of Business Administration, Asia University, Taichung, Taiwan \\ ${ }^{2}$ Department of Industrial Management, National Taiwan University of Science and Technology, Taipei, Taiwan \\ ${ }^{3}$ Nankang Rubber Tire Corp., Ltd., Taipei, Taiwan
}

Correspondence should be addressed to Yeneneh Tamirat; yyeennee@yahoo.com

Received 19 April 2017; Revised 8 September 2017; Accepted 17 September 2017; Published 30 October 2017

Academic Editor: Anna M. Gil-Lafuente

Copyright (c) 2017 Yeneneh Tamirat et al. This is an open access article distributed under the Creative Commons Attribution License, which permits unrestricted use, distribution, and reproduction in any medium, provided the original work is properly cited.

\begin{abstract}
We present four new sampling schemes by variables inspection to deal with the first-order autoregressive model between linear profiles. The first plan is based on exponentially weighted moving average (EWMA) and the rest of three plans are using the resubmitted sampling, repetitive group sampling (RGS), and multiple dependent state (MDS) sampling schemes. The nonlinear optimization problem is developed to find the number of profiles and the corresponding acceptance criteria, such that the producer's and consumer's risk are satisfied simultaneously. The efficiency of the proposed plans is compared with the conventional single sampling plan in terms of average sample number and the probability of acceptance. The result implies that all of the proposed sampling plans are superior to the single acceptance sampling plan by variables. In addition, the EWMA method appeared to be better than the others. The applications of proposed plans are shown with the help of industrial examples taken from calibration of an optical imaging system, and tire cornering stiffness test.
\end{abstract}

\section{Introduction}

Functional profiles express the relationship between one or more explanatory variables, the controllable inputs and a response variable which is the critical-to-quality characteristics. Thus, in statistical profile monitoring instead of individual or vector of quality characteristics we monitor the curve. Montgomery [1] defines a profile that is characterized by a functional relationship between a response variable and one or more independent variables. For example, profile monitoring has extensive application in the calibration of an optical imaging system; in tire cornering stiffness test the relationship between force and displacement can be modeled by linear profile. The fundamental concepts, methods, and issues regarding linear and nonlinear profiles monitoring methods can be found in [2]. A process yield index $S_{p k A}$ with the lower confidence bound for simple nonlinear and linear profiles can be found in [3] and [4], respectively. In the presence of autocorrelation between profiles [5] developed a process yield index $S_{p k A ; \operatorname{AR}(1)}$ with its approximate lower confidence bound. The author's simulation study confirmed the method performs well-regarding bias and coverage rate.

Acceptance sampling plans lay down conditions for acceptance or rejection of the immediate lot inspected. Process capability is of utmost importance in acceptance sampling; in no event should the requirements of a sampling procedure exceed the producer's process capability [6]. Moreover, in a highly competitive environment, sampling plans must be appropriately applied. In practice, the fraction of defectives a customer is willing to accept is getting very small, often measured in parts per million. That is, in order to reflect the actual lot quality, the sample size must be very large. In such circumstances, various authors [7-10] found variables 
sampling plans based on capability indices to be the most efficient methods of lot sentencing. In addition, variables sampling plans, based on the exponentially weighted moving average (EWMA) statistic, resubmitted sampling, repetitive group sampling (RGS), and multiple dependent state (MDS) sampling are proved to guarantee a reduction in sample size [11]. However, each sampling scheme should be applied cautiously to different scenarios. The scenarios are described as follows.

Scenario one: when the relationships between suppliers and customers have a long-term orientation, say ten or more previous lots are accepted, there would be an accumulated quality history. The EWMA sampling scheme takes into consideration past histories of the supplier to accept or reject the immediate lot inspected. The weights decline geometrically with the time of the observations. In quality control charts this EWMA statistic is known to be efficient to detect a small shift in the process [12-14]. Aslam et al. [15] applied the EWMA statistic in an acceptance sampling plan. For a process with linear profiles, [16] provided a single variable sampling plan based on EWMA model using the yield index $S_{p k A}$. In the literature Aslam et al. [15] and Wang [16] suggested that a sampling plan based on EWMA yield index for a normal process and a process with linear profiles has more flexibility and economy than the single sampling plan based on yield index while providing the same protection to both suppliers and buyers. More information about EWMA sampling plan can be found in [17].

Scenario two: if either the producer or the consumer does not agree with the sample inspection result, resubmission might be necessary for reaching an appropriate decision. That is, if a lot is not accepted, then a resubmitted lot is tested and a decision is made irrespective of the previous test. In resubmitted sampling plans for a normal process, Liu et al. [19] propose variables sampling plan for two-sided specification; [20] presented the operating procedure of the resubmitted sampling plan based on one-sided capability indices. When the data can be considered as identically, independently, and normally distributed linear profiles, [21] proposed variables sampling plan for resubmitted lots based on the yield index $S_{p k A}$. The author found that the resubmitted sampling plan has better-operating characteristics curve (OC) than single sampling plan. Other research related to sampling inspection for resubmitted lots can be found in the literature [22].

Scenario three: in some situations testing is costly and destructive; a small sample is taken from the lot and analyzed. In the case of noncompliance, the second small sample is taken from the lot and analyzed. This process is repeated till the lot is accepted or rejected. The procedure is similar to sequential sampling. Balamurali and Jun [23] reported that the RGS plan is more efficient in terms of average sample number (ASN), cost, and time than single and double sampling plans. When the inspection is costly and destructive an RGS by variables based on yield index $C_{p k}$ can be found in [24]. More information on RGS can be found in the literature $[25,26]$.
Scenario four: when the test result is marginal there might be a feeling the result is an inaccurate representation of the quality submitted. The inspection efficiency in such instances can be improved by utilizing the accumulated quality history of previous lots information. The MDS sampling plans are not only based on the current lot, but also on preceding lots [27]. With the absence of autocorrelation between linear profiles, [16] provided MDS sampling plan based on yield index $S_{p k A}$. More information on MDS can be found in the literature [28].

The principal advantage of variables plans is the reduction in sample size. It must be remembered, however, that the superiority of the variables plan rests on the assumption of the underlying distribution of the measurements [6]. Whether the performance measure is single quality characteristic [7-10,15] or profile data [16, 21] sampling schemes in the literature share two basic assumptions: the quality characteristic follows a normal distribution and data is independent. However, in some manufacturing processes, data is correlated or self-dependent. The effect of autocorrelations on the statistical properties of yield indices can be found in [5]. Accordingly, when dealing with sampling plans based on yield index the autocorrelation effect has to be taken into consideration. However, to the best of our knowledge, there is no work on sampling plan in the literature to deal with autocorrelation between profiles. In this study, we propose four new acceptance sampling plans based on the yield index for a first-order autoregressive process. The first method is based on EWMA. The remaining three are based on resubmitted sampling, RGS, and MDS sampling, respectively. The rest of the paper is organized as follows. In the next section, yield index for autocorrelation between linear profiles is reviewed. Four sampling plans by variables are presented in Section 3. In the subsequent section, the performances of the proposed plans are compared and two illustrative examples are provided in Section 5. The former is based on the line widths of three photomask reference standards; the latter is an experimental example for tire cornering stiffness test on the ice road. Finally, we offer a conclusion and suggestions for future studies.

\section{Yield Index for Autocorrelation between Linear Profiles}

The profiles addressed in this paper are of the form of autocorrelation between linear profiles given as

$$
\begin{aligned}
& y_{i j}=\alpha+\beta x_{i}+\varepsilon_{i j}, \\
& \varepsilon_{i j}=\rho \varepsilon_{i(j-1)}+a_{i j}, \\
& \quad i=1,2, \ldots, n, j=1,2, \ldots, k,
\end{aligned}
$$

where $n$ represents the number of levels and $k$ is the number of profiles. For each of the $k$ profiles, the response $y$ is measured at the same $n$ fixed locations called levels, where $x_{i}$ is the $i$ th level of the independent variable, $\rho$ denotes the 
first-order autoregressive coefficient, $\varepsilon_{i j}$ denotes correlated random error, $\alpha$ and $\beta$ are the intercept and slope of linear profiles, respectively, and $a_{i j} \sim N\left(0, \sigma^{2}\right)$.

Wang and Tamirat [5] derived the following process yield index for autocorrelation between linear profiles. This index is used to describe the relationship between manufacturing specifications and actual process yield.

$$
\widehat{S}_{p k A ; \mathrm{AR}(1)}=\frac{1}{3} \Phi^{-1}\left[\frac{1}{2}\left\{1+\frac{1}{n} \sum_{i=1}^{n}\left[2 \Phi\left(3 \widehat{S}_{p k_{i}}\right)-1\right]\right\}\right]
$$

where

$$
\begin{aligned}
S_{p k_{i}} & =\frac{1}{3} \Phi^{-1}\left[\frac{1}{2} \Phi\left(\frac{\mathrm{USL}_{i}-\mu_{i}}{\sigma_{i}}\right)+\frac{1}{2} \Phi\left(\frac{\mu_{i}-\mathrm{LSL}_{i}}{\sigma_{i}}\right)\right] \\
& =\frac{1}{3} \Phi^{-1}\left[\frac{1}{2} \Phi\left(\frac{1-C_{d r_{i}}}{C_{d p_{i}}}\right)+\frac{1}{2} \Phi\left(\frac{1+C_{d r_{i}}}{C_{d p_{i}}}\right)\right]
\end{aligned}
$$

where $\mu_{i}$ and $\sigma_{i}$ are the process mean and standard deviation of the response variable at the $i$ th level of the independent variable, $\mathrm{USL}_{i}$ and $\mathrm{LSL}_{i}$ are the upper and lower specification limits of the response variable at the $i$ th level of the independent variable, respectively, $C_{d r_{i}}=\left(\mu_{i}-m_{i} / d_{i}\right), C_{d p_{i}}=\sigma_{i} / d_{i}$, $m_{i}=\mathrm{USL}_{i}+\mathrm{LSL}_{i} / 2, d_{i}=\mathrm{USL}_{i}-\mathrm{LSL}_{i} / 2, \Phi$ is the cumulative distribution function of a standard random normal distribution, and $\Phi^{-1}$ is the inverse function of $\Phi$. Furthermore, [5] derived the asymptotic normal distribution of index $\widehat{S}_{p k A ; \operatorname{AR}(1)}$, which is given as follows:

$$
\begin{gathered}
\widehat{S}_{p k A ; \mathrm{AR}(1)} \sim N\left(S_{p k A ; \mathrm{AR}(1)}+\sum_{i=1}^{n} \frac{1}{12 n \phi\left(3 S_{p k A ; \mathrm{AR}(1)}\right)}\right. \\
\left.\cdot\left[a_{i}(1-f)\right], \frac{\sum_{i=1}^{n}\left[k a_{i}^{2} F /(k-1)^{2}+b_{i}^{2} g\right]}{36 n^{2} k \phi\left(3 S_{p k A ; \mathrm{AR}(1)}\right)^{2}}\right),
\end{gathered}
$$

where

$$
\begin{aligned}
& a_{i}=\frac{d_{i}}{\sqrt{2} \sigma_{i}\left\{\left(1-C_{d r_{i}}\right) \phi\left(\left(1-C_{d r_{i}}\right) / C_{d p_{i}}\right)+\left(1+C_{d r_{i}}\right) \phi\left(\left(1+C_{d r_{i}}\right) / C_{d p_{i}}\right)\right\}}, \\
& b_{i}=\phi\left(\frac{1-C_{d r_{i}}}{C_{d p_{i}}}\right)-\phi\left(\frac{1+C_{d r_{i}}}{C_{d p_{i}}}\right), \\
& f=1-\frac{2}{k(k-1)} \sum_{i=1}^{k-1}(k-i) \rho i, \\
& F=k+2 \sum_{i=1}^{k-1}(k-i) \rho^{2 i}+\frac{1}{k^{2}}\left[k+2 \sum_{i=1}^{k-1}(k-i) \rho^{i}\right]^{2}-\frac{2}{k} \sum_{i=0}^{k-1} \sum_{j=0}^{k-i}(k-i-j) \rho^{i} \rho^{j},
\end{aligned}
$$

where $\rho_{i}$ is the $i$ th lag autocorrelation and $\phi$ is the probability density function of a standard normal distribution.

\section{Acceptance Sampling Plans}

A sampling plan must satisfy two conditions: (1) the probability of accepting a lot at the acceptable quality level (AQL) is greater than the producer's confidence level $1-\alpha$ and (2) the probability of accepting a lot at the lot tolerance proportion defect (LTPD) is smaller than the consumer's risk $\beta$. Thus, for a particular sampling scheme its operating characteristic (OC) curve must pass through those two designated points (AQL, $1-\alpha$ ) and (LTPD, $\beta$ ). EWMA, resubmitted, RGS, and MDS sampling schemes based on $S_{p k A ; A R(1)}$ are presented and discussed in the following four subsections. The selection of a sampling scheme is based on purpose and information availability as discussed in the introduction part.

3.1. Sampling Plan Based on EWMA Model. The proposed sampling plan is given as follows.
Step 1. Choose the producer's risk and consumer's risk. Select the process yield requirements $\left(C_{\mathrm{AQL}}, C_{\mathrm{LTPD}}\right)$ at two risks.

Step 2. Take a random sample of linear profiles $k$ from the current lot and compute the process yield index $\widehat{S}_{p k A ; \mathrm{AR}(1)}^{t}$.

Step 3. Collect process yield indices from previous lots and compute the EWMA statistic $Z_{t}$.

The EWMA model with yield index proposed by [29] is given by

$$
Z_{t}=\lambda \widehat{S}_{p k A ; \operatorname{AR}(1)}^{t}+(1-\lambda) Z_{t-1}
$$

where $\widehat{S}_{p k A ; \mathrm{AR}(1)}^{t}$ is process yield index from current lot, $Z_{t-1}$ is obtained from previous lots, and $\lambda$ is smoothing constant and ranges from 0 to 1 . The choice of the optimal EWMA parameter is based on minimizing the error sum of squares from previous lots, $\mathrm{SSE}=\sum_{t=2}^{T}\left(Z_{t}-\widehat{S}_{p k A ; \mathrm{AR}(1) ; t}\right)^{2}$, where $Z_{2}=$ $\widehat{S}_{p k A ; A R(1) ; 1}$. Wang and Tamirat [5] apply the first-order expansion of $v$-variate Taylor and central limit theorem to derive the asymptotic normal distribution of index $\widehat{S}_{p k A ; \operatorname{AR}(1)}$; see (4). 
The properties of EWMA can be obtained from the formula for the sum of a geometric series. The variance of the EWMA statistic is derived by $\sigma_{E_{t}}^{2}=\left[\left\{1-(1-\lambda)^{2 t}\right\} \lambda /(2-\lambda)\right] \sigma^{2}$. When the process is in-control, $(1-\lambda)^{2 t} \rightarrow 0$, the variance of the EWMA statistic becomes $\sigma_{E_{t}}^{2}=\{\lambda /(2-\lambda)\} \sigma^{2}$ [12]. In a steady state process, the mean and variance of $X_{t}$ are obtained as $S_{p k A ; \mathrm{AR}(1)}+\sum_{i=1}^{n}\left(\left[a_{i}(1-f)\right] / 12 n \phi\left(3 S_{p k A ; \mathrm{AR}(1)}\right)\right)$ and $\operatorname{var}\left(X_{t}\right)=$ $(\lambda /(2-\lambda))\left(\sum_{i=1}^{n}\left[k a_{i}^{2} F /(k-1)^{2}+b_{i}^{2} g\right] / 36 n^{2} k \phi\left(3 S_{p k A ; \operatorname{AR}(1)}\right)^{2}\right)$, respectively. According to Montgomery [1], the EWMA can be viewed as a weighted average of all past and current observations; it is very insensitive to the normality assumption.

Step 4 (make a decision). Accept the lot if $Z_{t} \geq c_{a}$, where $c_{a}$ is the critical value; otherwise reject it.

The lot acceptance probability, say $P_{A}\left(Z_{t}\right)$, is established

$$
P_{A}\left(Z_{t} \geq k_{a}\right)=1-\Phi\left[\frac{k_{a}-\left(S_{p k A ; \mathrm{AR}(1)}+\sum_{i=1}^{n}\left(1 / 12 n \phi\left(3 S_{p k A ; \mathrm{AR}(1)}\right)\right)\left[a_{i}(1-f)\right]\right)}{\sqrt{(\lambda /(2-\lambda))\left(\sum_{i=1}^{n}\left[k a_{i}^{2} F /(k-1)^{2}+b_{i}^{2} g\right] / 36 n^{2} k \phi\left(3 S_{p k A ; \mathrm{AR}(1)}\right)^{2}\right)}}\right] .
$$

When $\lambda=1$, this sampling plan becomes a single sampling plan based on linear profiles. The ASN for this sampling plan is $k$. The parameters of our proposed plan are determined through the following nonlinear optimization problem:

Minimize $k$

$$
\begin{aligned}
\text { Subject to } & 1-\Phi\left(\frac{k_{a}-\left(C_{\mathrm{AQL}}+\sum_{i=1}^{n}\left(1 / 12 n \phi\left(3 C_{\mathrm{AQL}}\right)\right)\left[a_{i}(1-f)\right]\right)}{\sqrt{(\lambda /(2-\lambda))\left(\sum_{i=1}^{n}\left[k a_{i}^{2} F /(k-1)^{2}+b_{i}^{2} g\right] / 36 n^{2} k \phi\left(3 C_{\mathrm{AQL}}\right)^{2}\right)}}\right) \geq 1-\alpha, \\
& 1-\Phi\left(\frac{k_{a}-\left(C_{\mathrm{LTPD}}+\sum_{i=1}^{n}\left(1 / 12 n \phi\left(3 C_{\mathrm{LTPD}}\right)\right)\left[a_{i}(1-f)\right]\right)}{\sqrt{(\lambda /(2-\lambda))\left(\sum_{i=1}^{n}\left[k a_{i}^{2} F /(k-1)^{2}+b_{i}^{2} g\right] / 36 n^{2} k \phi\left(3 C_{\mathrm{LTPD}}\right)^{2}\right)}}\right) \leq \beta,
\end{aligned}
$$

where, $C_{\mathrm{LTPD}}<C_{\mathrm{AQL}}$.

\subsection{Resubmitted Sampling Plan. Resubmission is allowed $r-1$} times excluding the first inspection. The resubmitted sampling plan based on $S_{p k A ; \operatorname{AR}(1)}$ is described below.

Step 1. Choose the producer's risk $(\alpha)$, the consumer's risk $(\beta)$, two process capability indices $\left(C_{\mathrm{AQL}}\right.$ and $\left.C_{\mathrm{LTPD}}\right)$, and resubmission $(r-1)$ times.

Step 2. Draw random linear profiles $k$ from a submitted lot and compute the $\widehat{S}_{p k A ; \operatorname{AR}(1)}$ value.
Step 3 (make a decision). Accept the lot if $\widehat{S}_{p k A ; \mathrm{AR}(1)} \geq c_{a}$, where $c_{a}$ is a critical value; otherwise resubmit a lot and go to Step 2. We can reject the lot if it is not accepted on the $r-1$ resubmission.

The lot acceptance probability, say $P_{A ; \text { resubmitted }}\left(\widehat{S}_{p k A ; A R(1)}\right)$, is established as

$$
P_{A ; \text { resubmitted }}\left(\widehat{S}_{p k A ; \mathrm{AR}(1)}\right)=1-\left\{1-P_{A}\left(\widehat{S}_{p k A ; \mathrm{AR}(1)}\right)\right\}^{r} \text {, }
$$

where

$$
P_{A}\left(\widehat{S}_{p k A ; \mathrm{AR}(1)}\right)=1-\Phi\left[\frac{k_{a}-\left(S_{p k A ; \mathrm{AR}(1)}+\sum_{i=1}^{n}\left(1 / 12 n \phi\left(3 S_{p k A ; \mathrm{AR}(1)}\right)\right)\left[a_{i}(1-f)\right]\right)}{\sqrt{\sum_{i=1}^{n}\left[k a_{i}^{2} F /(k-1)^{2}+b_{i}^{2} g\right] / 36 n^{2} k \phi\left(3 S_{p k A ; \mathrm{AR}(1)}\right)^{2}}}\right] .
$$


The ASN for this resubmitted sampling plan is given as follows

$$
\mathrm{ASN}_{\text {resubmitted }}=\frac{k\left(1-\left[1-P_{A}\left(\widehat{S}_{p k A ; \mathrm{AR}(1)}\right)\right]^{r}\right)}{P_{A}\left(\widehat{S}_{p k A ; \mathrm{AR}(1)}\right)} .
$$

The plan parameters of this scheme will be determined from the solution to the following nonlinear optimization problem:

$$
\begin{array}{ll}
\text { Minimize } & \mathrm{ASN}_{\text {resubmitted }} \\
\text { Subject to } & 1-\left(\Phi\left[\frac{k_{a}-\left(C_{\mathrm{AQL}}+\sum_{i=1}^{n}\left(1 / 12 n \phi\left(3 C_{\mathrm{AQL}}\right)\right)\left[a_{i}(1-f)\right]\right)}{\sqrt{\sum_{i=1}^{n}\left[k a_{i}^{2} F /(k-1)^{2}+b_{i}^{2} g\right] / 36 n^{2} k \phi\left(3 C_{\mathrm{AQL}}\right)^{2}}}\right]\right)^{r} \geq 1-\alpha, \\
& 1-\left(\Phi\left[\frac{k_{a}-\left(C_{\mathrm{LTPD}}+\sum_{i=1}^{n}\left(1 / 12 n \phi\left(3 C_{\mathrm{LTPD}}\right)\right)\left[a_{i}(1-f)\right]\right)}{\sqrt{\sum_{i=1}^{n}\left[k a_{i}^{2} F /(k-1)^{2}+b_{i}^{2} g\right] / 36 n^{2} k \phi\left(3 C_{\mathrm{LTPD}}\right)^{2}}}\right]\right)^{r} \leq \beta,
\end{array}
$$

where $C_{\mathrm{LTPD}}<C_{\mathrm{AQL}}$.

3.3. Repetitive Group Sampling Plan. The RGS plan based on $S_{p k A ; \mathrm{AR}(1)}$ is described as follows.

Step 1. Choose the producer's risk, the consumer's risk, and two process capability indices $\left(C_{\mathrm{AQL}}\right.$ and $\left.C_{\mathrm{LTPD}}\right)$.

Step 2. Draw random linear profiles $k$ from a submitted lot and compute the $\widehat{S}_{p k A ; \operatorname{AR}(1)}$ value.

Step 3 (make a decision). Accept the lot if $\widehat{S}_{p k A ; \mathrm{AR}(1)} \geq c_{a}$, and reject the lot if $\widehat{S}_{p k A ; \mathrm{AR}(1)}<c_{r}$, where $c_{a}$ and $c_{r}$ are critical values; otherwise repeat Step 2.

The lot acceptance probability, say $P_{A ; \mathrm{RGS}}\left(\widehat{S}_{p k A ; \mathrm{AR}(1)}\right)$, is established as

$$
\begin{aligned}
& P_{A ; \mathrm{RGS}}\left(\widehat{S}_{p k A ; \mathrm{AR}(1)}\right) \\
& =\frac{P_{A}\left(S_{p k A ; \mathrm{AR}(1)} \geq c_{a}\right)}{P_{A}\left(S_{p k A ; \mathrm{AR}(1)} \geq c_{a}\right)+P_{A}\left(S_{p k A ; \mathrm{AR}(1)}<c_{r}\right)} .
\end{aligned}
$$

The ASN for this RGS sampling plan is given as follows:

$$
\begin{aligned}
\operatorname{ASN}_{\mathrm{RGS}}\left(C_{\mathrm{LTPD}}\right) & \\
= & \frac{k}{P_{A}\left(S_{p k A ; \mathrm{AR}(1)} \geq c_{a}\right)+P_{A}\left(S_{p k A ; \mathrm{AR}(1)}<c_{r}\right)} .
\end{aligned}
$$

When $c_{a}=c_{r}$, this RGS plan becomes a traditional single sampling plan.
The parameters of the repetitive sampling plan can be determined through the following nonlinear optimization problem:

Minimize ASN $_{\mathrm{RGS}}$

$$
\begin{array}{ll}
\text { Subject to } & \frac{P_{A}\left(C_{\mathrm{AQL}} \geq k_{a}\right)}{P_{A}\left(C_{\mathrm{AQL}} \geq k_{a}\right)+P_{A}\left(C_{\mathrm{AQL}}<k_{r}\right)} \\
& \geq 1-\alpha, \\
& \frac{P_{A}\left(C_{\mathrm{LTPD}} \geq k_{a}\right)}{P_{A}\left(C_{\mathrm{LTPD}} \geq k_{a}\right)+P_{A}\left(C_{\mathrm{LTPD}}<k_{r}\right)} \leq \beta,
\end{array}
$$

where $0<c_{r}<c_{a}$ and $C_{\mathrm{LTPD}}<C_{\mathrm{AQL}}$.

3.4. Multiple Dependent State Sampling Plan. The MDS sampling plan based on $S_{p k A ; \mathrm{AR}(1)}$ is described as follows.

Step 1. Choose the producer's risk, the consumer's risk, two process capability indices $\left(C_{\mathrm{AQL}}\right.$ and $\left.C_{\mathrm{LTPD}}\right)$, and the number of proceeding lots " $l$."

Step 2. Draw random linear profiles $n$ from a submitted lot and compute the $\widehat{S}_{p k A ; \mathrm{AR}(1)}$ value.

Step 3 (make a decision). (1) Accept the lot if $\widehat{S}_{p k A ; \mathrm{AR}(1)} \geq c_{a}$ and reject the lot if $\widehat{S}_{p k A ; \operatorname{AR}(1)}<c_{r}$, where $c_{a}$ and $c_{r}$ are critical values; (2) accept the current lot if the proceeding $l$ lots were accepted under the condition of $\widehat{S}_{p k A ; \operatorname{AR}(1)} \geq c_{a}$; otherwise repeat Step 2.

The lot acceptance probability, say $P_{A ; \mathrm{MDS}}\left(\widehat{S}_{p k A ; \mathrm{AR}(1)}\right)$, is established as

$$
P_{A ; \mathrm{MDS}}\left(S_{p k A ; \mathrm{AR}(1)}\right)=\frac{P_{1}\left(S_{p k A ; \mathrm{AR}(1)}\right)}{1-P_{\text {repetitive }}\left(S_{p k A ; \mathrm{AR}(1)}\right)},
$$


where $P_{1}\left(\widehat{S}_{p k A ; \operatorname{AR}(1)}\right)=P\left(\widehat{S}_{p k A ; \operatorname{AR}(1)} \geq k_{a}\right)+P\left(k_{r} \leq \widehat{S}_{p k A ; \operatorname{AR}(1)}<\right.$ $\left.k_{a}\right)\left[P\left(\widehat{S}_{p k A ; \mathrm{AR}(1)} \geq k_{a}\right)\right]^{l}$ and $P_{\text {repetitive }}\left(S_{p k A ; \mathrm{AR}(1)}\right)=P\left(k_{r} \leq\right.$ $\left.\widehat{S}_{p k A ; \mathrm{AR}(1)}<k_{a}\right)\left(1-\left[P\left(\widehat{S}_{p k A ; \mathrm{AR}(1)} \geq k_{a}\right)\right]^{l}\right)$.

The average sample number for the MDS plan is established as

$$
\begin{aligned}
& \mathrm{ASN}_{\mathrm{MDS}} \\
& =\frac{1}{2}\left\{\frac{k}{1-P\left(c_{r} \leq \widehat{S}_{p k A ; \mathrm{AR}(1)}<c_{a}\right)\left(1-\left[P\left(\widehat{S}_{p k A ; \mathrm{AR}(1)} \geq c_{a}\right)\right]^{l}\right)}\right. \\
& \left.+\frac{k}{1-P\left(c_{r} \leq \widehat{S}_{p k A ; \mathrm{AR}(1)}<c_{a}\right)\left[P\left(\widehat{S}_{p k A ; \mathrm{AR}(1)} \geq c_{a}\right)\right]^{l}}\right\} .
\end{aligned}
$$

When $l=0$, this MDS plan becomes the RGS plan.

The parameters of the MDS sampling plan can be determined through the following nonlinear optimization problem:

$$
\begin{array}{ll}
\text { Minimize } & \mathrm{ASN}_{\mathrm{MDS}} \\
\text { Subject to } & \frac{P_{1}\left(C_{\mathrm{AQL}}\right)}{1-P_{\text {repetitive }}\left(C_{\mathrm{AQL}}\right)} \geq 1-\alpha, \\
& \frac{P_{1}\left(C_{\mathrm{LTPD}}\right)}{1-P_{\text {repetitive }}\left(C_{\mathrm{LTPD}}\right)} \leq \beta,
\end{array}
$$

where $0<k_{r}<k_{a}, C_{\mathrm{LTPD}}<C_{\mathrm{AQL}}, P_{1}\left(C_{\mathrm{AQL}}\right)$, and $P_{\text {repetitive }}\left(C_{\mathrm{AQL}}\right)$ are obtained by (19).

\section{Comparison Study}

In this section, the average sample numbers and probability of acceptance of the proposed plans are compared. Computations are carried out using computer programs written in the $\mathrm{R}$ language [30]. The programs are available from the authors. For instance, in order to determine the plan parameters for different combinations of $\left(C_{\mathrm{AQL}}, C_{\mathrm{LTPD}}\right)$ using the sampling plan based on EWMA model, we used a simple algorithm to search the space of possible solutions. It consists of the following three steps.

Step 1. Assuming $k$ ranges from 2 to 300 and $c_{a}$ is generated from a uniform distribution between $C_{\mathrm{LTPD}}$ and $C_{\mathrm{AQL}}, 1,000$ combinations of $k$ and $c_{a}$ were randomly generated.

Step 2. Evaluate 1,000 combinations of $\left(k, c_{a}\right)$ that must satisfy the two constraints (9) with the objective of minimizing the number of profiles.

Step 3. Repeat Steps 1 and 2 for 100 times to determine the optimal parameters.

As shown in Table 1 we consider some different combinations of $C_{\mathrm{AQL}}$ and $C_{\mathrm{LTPD}}$ at a specified producer's risk $(\alpha=0.05)$ and customer's risk $(\beta=0.1)$. The probability of acceptance and the average number of profiles were calculated for the specified plans. From Table 1 all the proposed

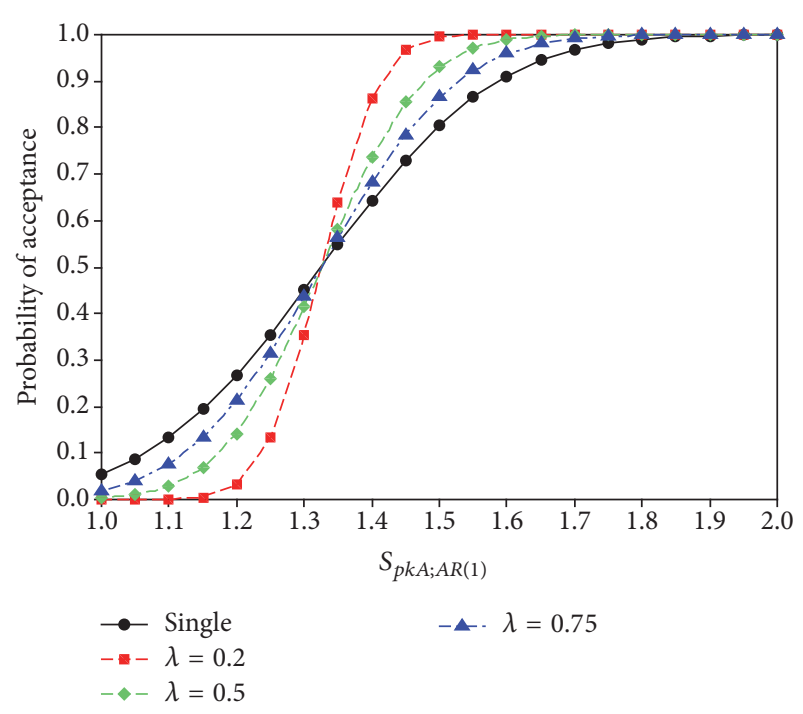

FIgURE 1: Comparison of EWMA OC curves under $k=100, c=$ 1.33 , and $\rho=0.5$.

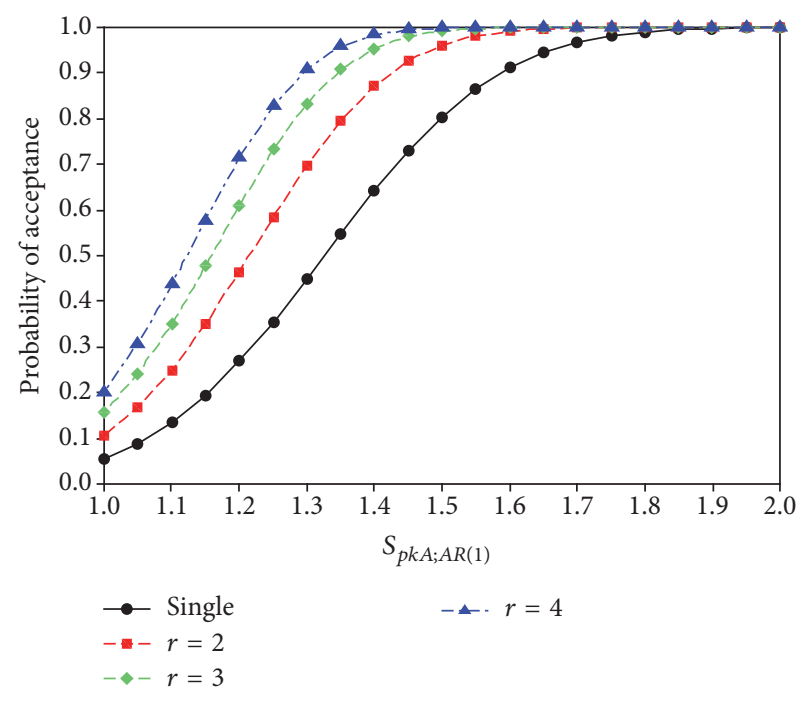

FIgURE 2: Comparison of resubmitted OC curves under $k=100$, $c=1.33$, and $\rho=0.5$.

methods outperform the existing single variable scheme. The EWMA requires the smallest average number of profiles. Furthermore, it can be observed that the difference in ASN values between the variables single sampling plan and the proposed sampling plans increases when the gap between $C_{\mathrm{AQL}}$ and $C_{\mathrm{LTPD}}$ narrows. This implies that, with the same protection level, the proposed plans will minimize the time and cost of inspection especially for cases when the process fraction of defectives required is very low.

The slope of the OC curves in Figures 1-4, respectively, displays the discriminatory power of the sampling scheme between good and bad lots. The steeper the slope of the OC curve, the greater the discriminatory power. Figures 1-4 also illustrate how different values of an input variable impact the sensitive the OC curves of each sampling scheme. Figure 1 
TABLE 1: Comparison of different sampling plans under $n=4, \rho=0.5$ to match at $\alpha=0.05$, and $\beta=0.1$.

\begin{tabular}{|c|c|c|c|c|c|}
\hline Case & $\begin{array}{l}\text { EWMA } \\
\lambda=0.25\end{array}$ & Resubmitted & RGS & MDS & $\begin{array}{c}\text { Single variable } \\
\lambda=1.00\end{array}$ \\
\hline $\begin{array}{l}C_{\mathrm{AQL}}=1.33 \\
C_{\mathrm{LTPD}}=1.10\end{array}$ & $\begin{array}{c}k=8 \\
c_{a}=1.2975 \\
P_{a 1}=0.9515 \\
P_{a 2}=0.0990 \\
\mathrm{ASN}=8\end{array}$ & $\begin{array}{c}k=30 \\
c_{a}=1.3239 \\
r=2 \\
P_{a 1}=0.9527 \\
P_{a 2}=0.0906 \\
\mathrm{ASN}=36.5\end{array}$ & $\begin{array}{c}k=33 \\
l=2 \\
c_{a}=1.2342 \\
c_{r}=1.0957 \\
P_{a 1}=0.9514 \\
P_{a 2}=0.0987 \\
\text { ASN }=39.9\end{array}$ & $\begin{array}{c}k=32 \\
l=2 \\
c_{a}=1.2214 \\
c_{r}=0.8577 \\
P_{a 1}=0.9510 \\
P_{a 2}=0.0999 \\
\text { ASN }=34.9\end{array}$ & $\begin{array}{c}k=48 \\
c_{a}=1.2988 \\
P_{a 1}=0.9518 \\
P_{a 2}=0.0848 \\
\text { ASN }=48\end{array}$ \\
\hline $\begin{array}{l}C_{\mathrm{AQL}}=1.33 \\
C_{\mathrm{LTPD}}=1.00\end{array}$ & $\begin{array}{c}k=5 \\
c_{a}=1.1526 \\
P_{a 1}=0.96781 \\
P_{a 2}=0.0962 \\
\text { ASN }=5\end{array}$ & $\begin{array}{c}k=14 \\
c_{a}=1.2884 \\
r=2 \\
P_{a 1}=0.9558 \\
P_{a 2}=0.0969 \\
\text { ASN }=16.9\end{array}$ & $\begin{array}{c}k=16 \\
c_{a}=1.1840 \\
c_{r}=0.9918 \\
P_{a 1}=0.9523 \\
P_{a 2}=0.0937 \\
\mathrm{ASN}=19.1\end{array}$ & $\begin{array}{c}k=15 \\
l=2 \\
c_{a}=1.1669 \\
c_{r}=0.8156 \\
P_{a 1}=0.9506 \\
P_{a 2}=0.0992 \\
\text { ASN }=16.4\end{array}$ & $\begin{array}{c}k=23 \\
c_{a}=1.2290 \\
P_{a 1}=0.9500 \\
P_{a 2}=0.0882 \\
\text { ASN }=23\end{array}$ \\
\hline $\begin{array}{l}C_{\mathrm{AQL}}=1.50 \\
C_{\mathrm{LTPD}}=1.35\end{array}$ & $\begin{array}{c}k=24 \\
c_{a}=1.4707 \\
P_{a 1}=0.9539 \\
P_{a 2}=0.0989 \\
\text { ASN }=24\end{array}$ & $\begin{array}{c}k=104 \\
c_{a}=1.4940 \\
r=2 \\
P_{a 1}=0.9532 \\
P_{a 2}=0.0938 \\
\mathrm{ASN}=126.5\end{array}$ & $\begin{array}{c}k=102 \\
c_{a}=1.4417 \\
c_{r}=1.3488 \\
P_{a 1}=0.9502 \\
P_{a 2}=0.0985 \\
\text { ASN }=124.9\end{array}$ & $\begin{array}{c}k=101 \\
l=2 \\
c_{a}=1.4321 \\
c_{r}=1.2756 \\
P_{a 1}=0.9514 \\
P_{a 2}=0.0993 \\
\text { ASN }=110\end{array}$ & $\begin{array}{c}k=155 \\
c_{a}=1.4713 \\
P_{a 1}=0.9518 \\
P_{a 2}=0.0985 \\
\text { ASN }=155\end{array}$ \\
\hline $\begin{array}{l}C_{\mathrm{AQL}}=1.50 \\
C_{\mathrm{LTPD}}=1.25\end{array}$ & $\begin{array}{c}k=9 \\
c_{a}=1.4237 \\
P_{a 1}=0.9511 \\
P_{a 2}=0.0904 \\
\text { ASN }=9\end{array}$ & $\begin{array}{c}k=33 \\
c_{a}=1.4993 \\
r=2 \\
P_{a 1}=0.9513 \\
P_{a 2}=0.09234 \\
\mathrm{ASN}=40.3\end{array}$ & $\begin{array}{c}k=36 \\
c_{a}=1.3938 \\
c_{r}=1.2537 \\
P_{a 1}=0.9521 \\
P_{a 2}=0.0998 \\
\text { ASN }=43.1\end{array}$ & $\begin{array}{c}k=35 \\
l=2 \\
c_{a}=1.3817 \\
c_{r}=1.1818 \\
P_{a 1}=0.9528 \\
P_{a 2}=0.0998 \\
\text { ASN }=38.1\end{array}$ & $\begin{array}{c}k=53 \\
c_{a}=1.4363 \\
P_{a 1}=0.9503 \\
P_{a 2}=0.0999 \\
\text { ASN }=53\end{array}$ \\
\hline $\begin{array}{l}C_{\mathrm{AQL}}=1.67 \\
C_{\mathrm{LTPD}}=1.50\end{array}$ & $\begin{array}{c}k=23 \\
c_{a}=1.6463 \\
P_{a 1}=0.9500 \\
P_{a 2}=0.0911 \\
\text { ASN }=23\end{array}$ & $\begin{array}{c}k=97 \\
c_{a}=1.6587 \\
r=2 \\
P_{a 1}=0.9503 \\
P_{a 2}=0.0982 \\
\text { ASN }=118.6\end{array}$ & $\begin{array}{c}k=99 \\
c_{a}=1.6058 \\
c_{r}=1.4871 \\
P_{a 1}=0.9513 \\
P_{a 2}=0.0966 \\
\text { ASN }=122.9\end{array}$ & $\begin{array}{c}k=98 \\
l=2 \\
c_{a}=1.5927 \\
c_{r}=1.3230 \\
P_{a 1}=0.9527 \\
P_{a 2}=0.0999 \\
\text { ASN }=106.7\end{array}$ & $\begin{array}{c}k=143 \\
c_{a}=1.6683 \\
P_{a 1}=0.9510 \\
P_{a 2}=0.0984 \\
\text { ASN }=143\end{array}$ \\
\hline $\begin{array}{l}C_{\mathrm{AQL}}=1.67 \\
C_{\mathrm{LTPD}}=1.40\end{array}$ & $\begin{array}{c}k=9 \\
c_{a}=1.6180 \\
P_{a 1}=0.95081 \\
P_{a 2}=0.0977 \\
\text { ASN }=9\end{array}$ & $\begin{array}{c}k=36 \\
c_{a}=1.6553 \\
r=2 \\
P_{a 1}=0.9557 \\
P_{a 2}=0.0984 \\
\text { ASN }=43.6\end{array}$ & $\begin{array}{c}k=39 \\
c_{a}=1.5531 \\
c_{r}=1.4175 \\
P_{a 1}=0.9513 \\
P_{a 2}=0.0984 \\
\text { ASN }=46.1\end{array}$ & $\begin{array}{c}k=37 \\
l=2 \\
c_{a}=1.5438 \\
c_{r}=1.3817 \\
P_{a 1}=0.9509 \\
P_{a 2}=0.0988 \\
\text { ASN }=40.3\end{array}$ & $\begin{array}{c}k=56 \\
c_{a}=1.6159 \\
P_{a 1}=0.9562 \\
P_{a 2}=0.0973 \\
\text { ASN }=56\end{array}$ \\
\hline
\end{tabular}

$P_{a 1}$ is probability of accepting at $C_{\mathrm{AQL}}$ and $P_{a 2}$ is probability of accepting at $C_{\mathrm{LTPD}}$.

indicates that the smaller the value of $\lambda$, the better the power. For example, if the quality level desired by the consumer is $S_{p k}=1.50$, the probability of acceptance at $\lambda$ values of 0.25 , $0.5,0.75$, and 1.0 became $1.0,0.99,0.96$, and 0.91 , respectively. That is, the associated producer's risk turned out to be 0 , $0.01,0.04$, and 0.09 , respectively. Figures 2 and 3 indicate that increasing the number of resubmissions and repetitions improves the power. For instance, at a given $C_{\mathrm{AQL}}=1.33$ and $C_{\mathrm{LTPD}}=1.00$, increasing the allowable resubmissions from two to four improves the probability of acceptance of a good lot from 0.96 to 0.99 . For the MDS the effect of a number of preceding lots on the power is very marginal. From these comparisons, we may conclude that all of the proposed sampling plans are superior to the variable single acceptance sampling plan in terms of power. Figure 5 compared the efficiency of the proposed sampling plans with an existing single sampling plan $(\lambda=1)$ at $C_{\mathrm{AQL}}=1.50, \alpha=0.05$, and $\beta=0.10$ for several values of $C_{\mathrm{LTPD}}=1.0(0.05) 1.4$. The result indicates that the EWMA sampling plan is more efficient in terms of average sample number than other four schemes, MDS is second best, and resubmitted and RGS are very close to each other.

As stated in the introduction each scheme is designed for specific purpose and information availability. For example, 


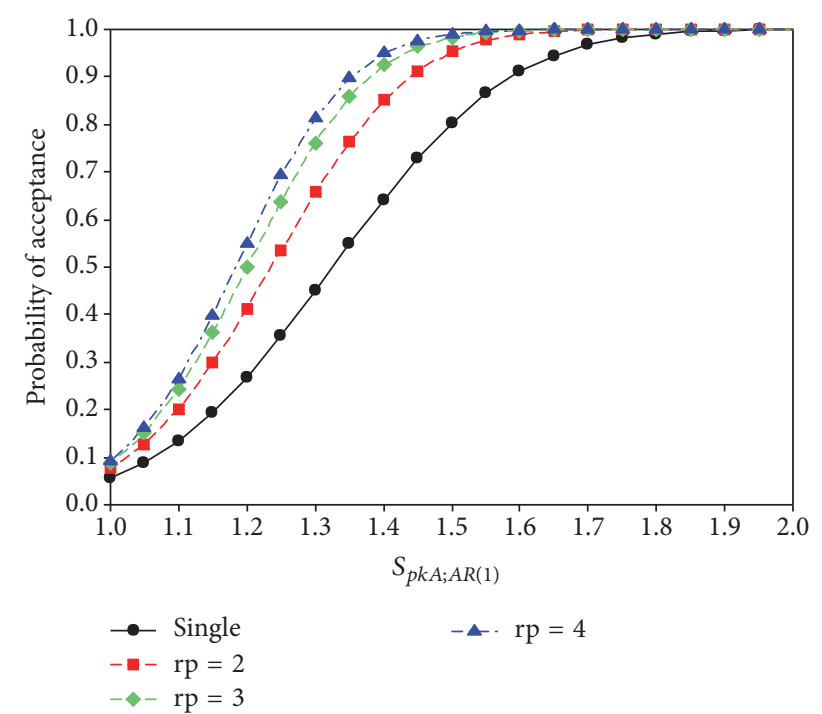

FIGURE 3: Comparison of RGS OC curves under $k=100, c=1.33$, and $\rho=0.5$. $\mathrm{rp}$ is replication.

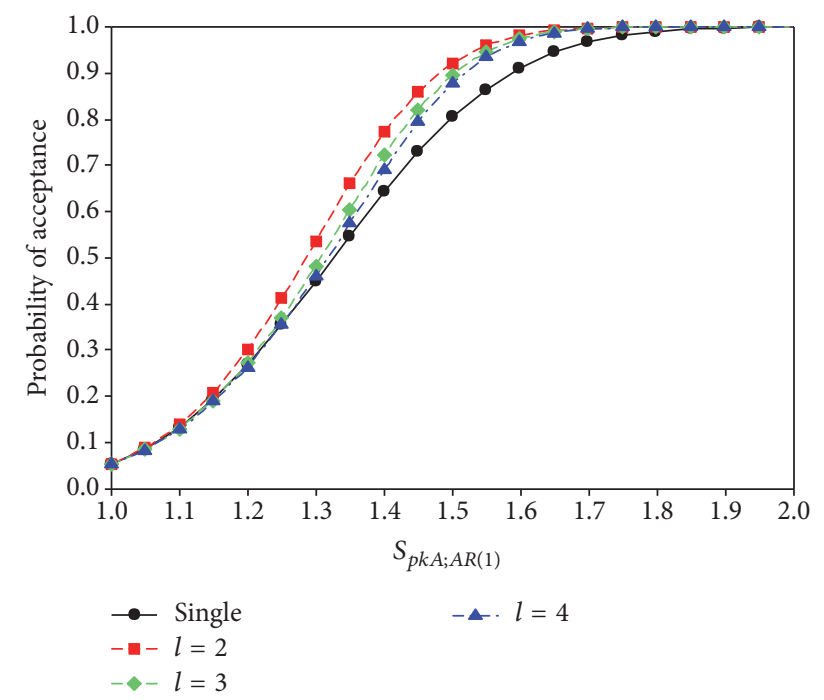

FIGURE 4: Comparison of MDS OC curves under $k=100, c=1.33$, and $\rho=0.5$.

EWMA is useful when ten or more previous lots are accepted. However, in some cases, data might be available for two or more methods, for such instances based on Table 1 and Figure 5 the EWMA technique appeared to be more efficient in terms of cost than the other methods. That is, it provides the smallest ASN.

\section{Illustrative Examples}

Example 1. We considered the calibration of an optical imaging system in [18]. The process is in statistical control, the functional profiles from phase I analysis resulted in an AR1 model, and the relationship between the response variable

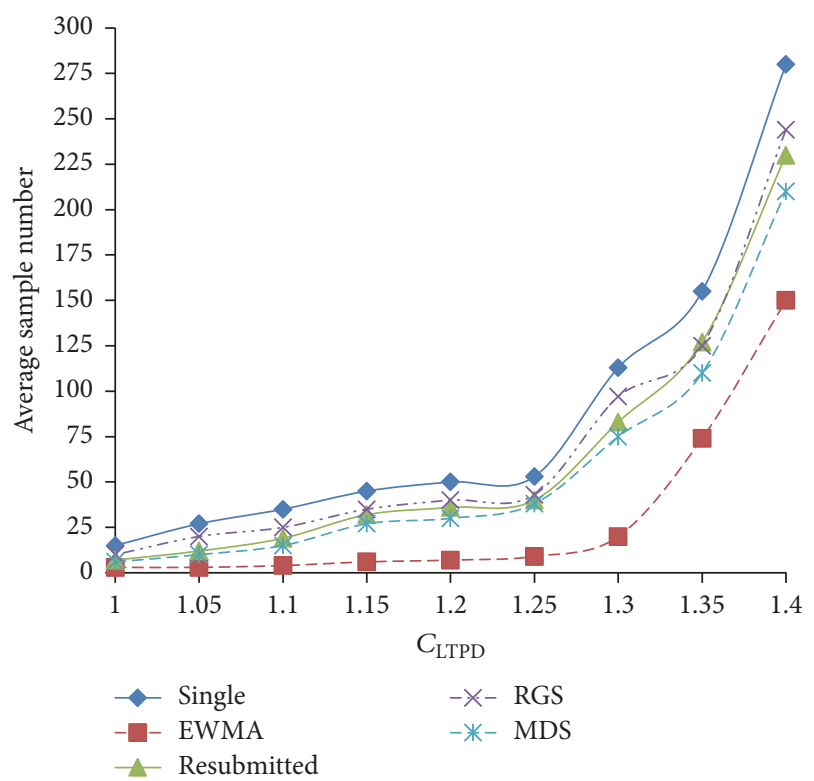

Figure 5: The average sample numbers under $C_{\mathrm{AQL}}=1.50, \alpha=0.05$, and $\beta=0.10$.

TABLE 2: Specification limits at each level for the line-width measurements modified from [18].

\begin{tabular}{ccccc}
\hline$i$ & $x_{i}$ & LSL $_{i}$ & USL $_{i}$ & Target $_{i}$ \\
\hline 1 & 0.76 & 0.70 & 1.30 & 1.024 \\
2 & 3.29 & 3.20 & 3.80 & 3.495 \\
3 & 8.89 & 8.70 & 9.30 & 8.965 \\
\hline
\end{tabular}

and the explanatory variable is modeled as $y_{i j}=0.2357+$ $0.9870 x_{i}+\varepsilon_{i j}, \varepsilon_{i j}=0.5 \varepsilon_{i(j-1)}+a_{i j}$ with a residual standard deviation of 0.07 . Table 2 shows specification limits of the response variable. Suppose that the values of $C_{\mathrm{AQL}}$ and $C_{\mathrm{LTPD}}$ are set to 1.50 and 1.25 and the two levels of risk $(\alpha, \beta)$ are set $(0.05,0.1)$. Table 3 depicts sample plans that are equivalent, since they all provide the same protection to both suppliers and customers. The EWMA technique provides the smallest ASN. The plan parameters are found to be $c_{a}=1.4057$ and $k=$ 26. Furthermore, the yield index $S_{p k A ; A R(1)}$ of 10 previously accepted lots are assumed to be $(1.4862,1.5112,1.5134,1.5034$, $1.4991,1.5002,1.4715,1.4908,1.4729$, and 1.4862) the optimal value of $\lambda$ is obtained as 0.1273 . We collected 26 profiles and the immediate lot inspected resulted in $S_{p k A ; \mathrm{AR}(1)}=1.2613$. The corresponding $Z_{t}$ value became 1.4637 since $Z_{t}$ is greater than 1.4057 according to the EWMA scheme; the current lot can be deemed as accepted.

Example 2. This example is a real case study from the automobile parts industry. The goal was to determine whether the experimental setup is acceptable or not. The procedure is used to simulate tire cornering stiffness on the ice road. The lab measurements were done on the plunger tester equipped with the servo-hydraulic system. Type of tire tested is regular production, commercially available tire (255/80R17.5) with snow tread. Tests were conducted by pull force developed by 

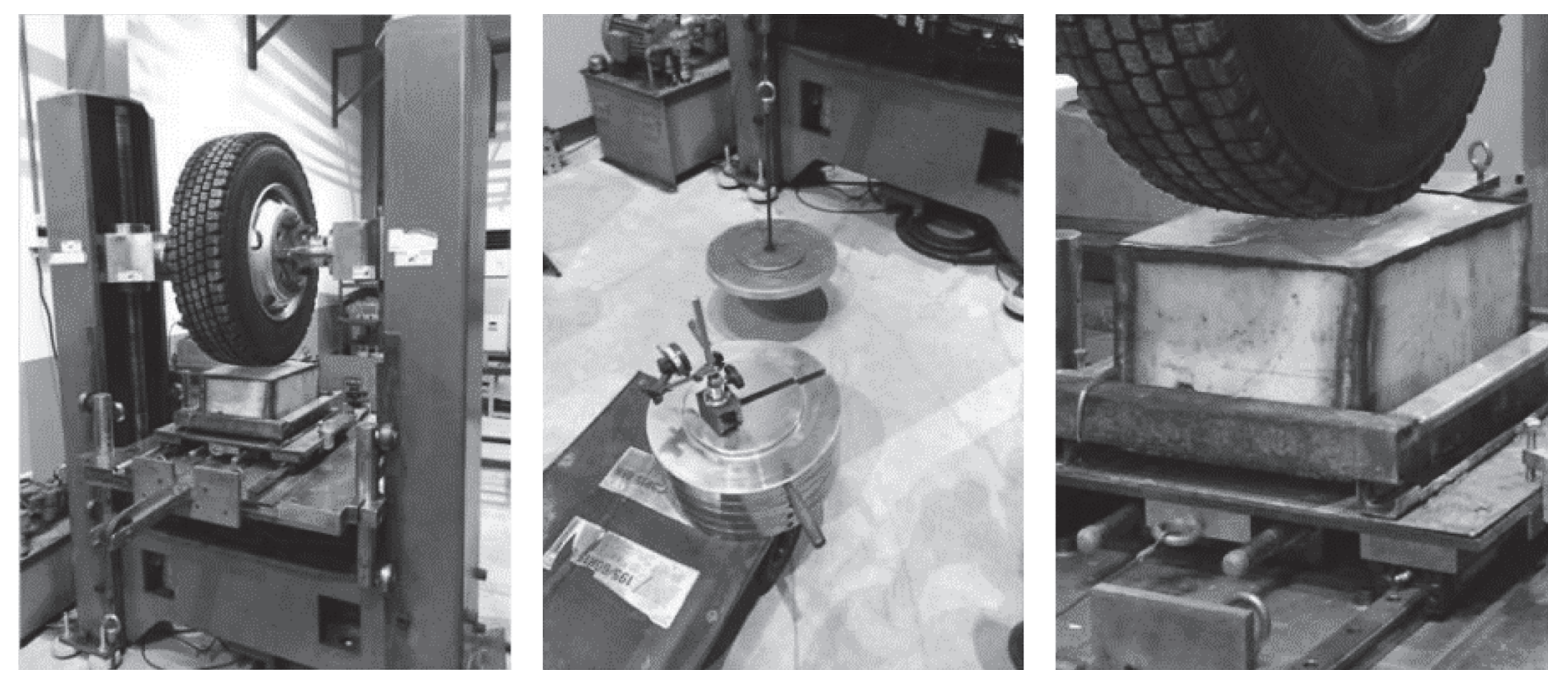

FIGURE 6: Experimental setup.

TABLE 3: Equivalent alternative sampling plans for line-width measurement.

\begin{tabular}{|c|c|c|c|c|}
\hline EWMA & $\begin{array}{l}\text { Resubmitted } \\
\quad(r=2)\end{array}$ & RGS & $\operatorname{MDS}(l=2)$ & $\begin{array}{c}\text { Single variable } \\
\lambda=1.00\end{array}$ \\
\hline $\begin{array}{l}\lambda=0.1273 \\
k=26 \\
c_{a}=1.4057 \\
P_{a 1}=0.9519 \\
P_{a 2}=0.0961 \\
\text { ASN }=26\end{array}$ & $\begin{array}{c}k=46 \\
c_{a}=1.4595 \\
r=2 \\
P_{a 1}=0.9518 \\
P_{a 2}=0.0913 \\
\text { ASN }=56.1\end{array}$ & $\begin{array}{c}k=50 \\
c_{a}=1.3887 \\
c_{r}=1.2806 \\
P_{a 1}=0.9502 \\
P_{a 2}=0.0940 \\
\text { ASN }=58\end{array}$ & $\begin{array}{c}k=46 \\
l=2 \\
c_{a}=1.3827 \\
c_{r}=1.1491 \\
P_{a 1}=0.9504 \\
P_{a 2}=0.0968 \\
\text { ASN }=50\end{array}$ & $\begin{array}{c}k=53 \\
c_{a}=1.4363 \\
P_{a 1}=0.9503 \\
P_{a 2}=0.0999 \\
\text { ASN }=53\end{array}$ \\
\hline
\end{tabular}

TABLE 4: Experiment output and specification limits.

\begin{tabular}{lcccc}
\hline Level & Weight & Target $_{i}$ & LSL & LSL $_{i}$ \\
\hline 1 & 20 & 0.12 & 0.04 & 0.2 \\
2 & 40 & 0.65 & 0.57 & 0.73 \\
3 & 60 & 1.37 & 1.29 & 1.45 \\
4 & 80 & 2.01 & 1.93 & 2.09 \\
5 & 100 & 2.85 & 2.77 & 2.93 \\
\hline
\end{tabular}

$20 \mathrm{~kg}$ counterweights; each time add a $20 \mathrm{~kg}$ counterweight and record the corresponding tire displacement. The maximum load is $100 \mathrm{~kg}$; that is, the measurement is taken at 20 , $40,60,80$, and $100 \mathrm{~kg}$, respectively. Table 4 shows the upper and lower specification limits at each level of the independent variable. The setup is shown in Figure 6, from left to right total experiment setup, counterweights, and close-up view of contact between tire and snow in a container.

Regression analysis was used to fit the relationship between force and displacement; we found that the relationship between the response variable and the explanatory variable can be modeled as $y_{i j}=0.034 x_{i}-0.646+\varepsilon_{i j}$, $\varepsilon_{i j}=0.27 \varepsilon_{i(j-1)}+a_{i j}$, with a residual standard deviation of 0.06 , where $x_{i}$ is the $i$ th level of the independent variable $(i=1,2, \ldots, 5)$. Suppose that the values of $C_{\mathrm{AQL}}$ and $C_{\mathrm{LTPD}}$ are set to 1.50 and 1.33 and the two levels of risk $(\alpha, \beta)$ are set $(0.05,0.1)$. Five equivalent sampling plans are provided in Table 5. However, since we do not have prior test information it is not possible to apply EWMA and MDS. The resubmitted scheme is more appropriate than repetitive; that is, if a test is not accepted, make an improvement on the setup and the next setup is tested and a decision is made irrespective of the previous test. After the second test we found $S_{p k A ; \mathrm{AR}(1)}=$ 1.4613 which is greater than the critical value, $c_{a}=1.4540$; it is possible to conclude the setup is acceptable.

\section{Conclusion}

In this paper, we developed four alternative acceptance sampling plans based on the process yield index $S_{p k A ; \mathrm{AR}(1)}$ to deal with lot sentencing for autocorrelation between linear profiles. The proposed sampling plans reduce significantly the average sample number as compared with the traditional single sampling plan. Under specific conditions, the proposed sampling plans become equal and reduced to a single sampling plan by variables. Since the EWMA method considers the quality history of the previous lots the number of profiles required is smaller than the other three sampling schemes. RGS and MDS schemes are equivalent; the advantage of MDS is it takes into consideration past history, which results in a reduction of cost and time of retesting. Resubmitted 
TABLE 5: Equivalent alternative sampling plans for tire test.

\begin{tabular}{|c|c|c|c|c|}
\hline EWMA & $\begin{array}{c}\text { Resubmitted } \\
\quad(r=2)\end{array}$ & RGS & $\operatorname{MDS}(l=2)$ & $\begin{array}{c}\text { Single variable } \\
\lambda=1.00\end{array}$ \\
\hline $\begin{array}{l}\lambda=0.150 \\
k=32 \\
c_{a}=1.4499 \\
P_{a 1}=0.9529 \\
P_{a 2}=0.0965 \\
\text { ASN }=32\end{array}$ & $\begin{array}{c}k=114 \\
c_{a}=1.4940 \\
r=2 \\
P_{a 1}=0.9532 \\
P_{a 2}=0.0938 \\
\mathrm{ASN}=126.5\end{array}$ & $\begin{array}{c}k=112 \\
c_{a}=1.4417 \\
c_{r}=1.3488 \\
P_{a 1}=0.9502 \\
P_{a 2}=0.0985 \\
\text { ASN }=124.9\end{array}$ & $\begin{array}{c}k=111 \\
l=2 \\
c_{a}=1.4321 \\
c_{r}=1.2756 \\
P_{a 1}=0.9514 \\
P_{a 2}=0.0993 \\
\text { ASN }=110\end{array}$ & $\begin{array}{c}k=167 \\
c_{a}=1.4713 \\
P_{a 1}=0.9518 \\
P_{a 2}=0.0985 \\
\text { ASN }=155\end{array}$ \\
\hline
\end{tabular}

and RGS schemes can be used to solve disputed inspection procedures.

\section{Conflicts of Interest}

The authors declare that there are no conflicts of interest regarding the publication of this paper.

\section{Acknowledgments}

This work was supported by the Ministry of Science and Technology in Taiwan under the Grant MOST 105-2218-E468-003.

\section{References}

[1] D. C. Montgomery, Introduction to statistical quality control, vol. 1, Wiley, New York, NY, USA, 6th edition, 2003.

[2] R. Noorossana, A. Saghaei, and A. Amiri, Statistical analysis of profile monitoring, Wiley, New York, NY, USA, 2011.

[3] F.-K. Wang and Y.-C. Guo, "Measuring process yield for nonlinear profiles," Quality and Reliability Engineering International, vol. 30, no. 8, pp. 1333-1339, 2014.

[4] F.-K. Wang, "A process yield for simple linear profiles," Quality Engineering, vol. 26, no. 3, pp. 311-318, 2014.

[5] F.-K. Wang and Y. Tamirat, "Process yield analysis for autocorrelation between linear profiles," Computers \& Industrial Engineering, vol. 71, no. 1, pp. 50-56, 2014.

[6] E. G. Schilling and D. V. Neubauer, Acceptance sampling in quality control, Statistics: Textbooks and Monographs, CRC Press, Boca Raton, FL, USA, 2nd edition, 2009.

[7] C.-W. Wu and S.-W. Liu, "Developing a sampling plan by variables inspection for controlling lot fraction of defectives," Applied Mathematical Modelling: Simulation and Computation for Engineering and Environmental Systems, vol. 38, no. 9-10, pp. 2303-2310, 2014

[8] L.-C. Sheu, C.-H. Yeh, C.-H. Yen, and C.-H. Chang, "Developing acceptance sampling plans based on incapability index Cpp," Applied Mathematics \& Information Sciences, vol. 8, no. 5, pp. 2509-2514, 2014.

[9] N. Kurniati, R.-H. Yeh, and C.-W. Wu, "Designing a variables two-plan sampling system of type TNTVSS-(nT, nN; K) for controlling process fraction nonconforming with unilateral specification limit," International Journal of Production Research, vol. 53, no. 7, pp. 2011-2025, 2015.
[10] S.-W. Liu and C.-W. Wu, "A quick switching sampling system by variables for controlling lot fraction nonconforming," International Journal of Production Research, vol. 54, no. 6, pp. 18391849,2016

[11] M. Aslam and F.-K. Wang, "Acceptance sampling plans for linear profiles with one-sided specifications," Journal of Statistical Computation and Simulation, vol. 87, no. 4, pp. 806-816, 2017.

[12] P. Čisar and S. M. Čisar, "Optimization methods of EWMA statistics," Acta Polytechnica Hungarica, vol. 8, no. 5, pp. 73-87, 2011.

[13] J. S. Hunter, "The exponentially weighted moving average," Journal of Quality Technology, vol. 18, no. 4, pp. 203-210, 1986.

[14] J. M. Lucas and M. S. Saccucci, "Exponentially weighted moving average control schemes: properties and enhancements," Technometrics, vol. 32, no. 1, pp. 1-29, 1990.

[15] M. Aslam, M. Azam, and C.-H. Jun, "A new lot inspection procedure based on exponentially weighted moving average," International Journal of Systems Science, vol. 46, no. 8, pp. 1392$1400,2015$.

[16] F.-K. Wang, "A Single Sampling Plan Based on Exponentially Weighted Moving Average Model for Linear Profiles," Quality and Reliability Engineering International, vol. 32, no. 5, pp. 17951805, 2016.

[17] M. Aslam, M. Azam, and C.-H. Jun, "Improved acceptance sampling plan based on EWMA statistic," Sequential Analysis. Design Methods \& Applications, vol. 34, no. 3, pp. 406-422, 2015.

[18] C. Croarkin and P. Tobias, NIST/SEMATECH e-handbook of statistical methods, U.S., Department of Commerce, 2012.

[19] S.-W. Liu, S.-W. Lin, and C.-W. Wu, "A resubmitted sampling scheme by variables inspection for controlling lot fraction nonconforming," International Journal of Production Research, vol. 52, no. 12, pp. 3744-3754, 2014.

[20] N. Kurniati, R.-H. Yeh, and C.-W. Wu, "A sampling scheme for resubmitted lots based on one-sided capability indices," Quality Technology and Quantitative Management, vol. 12, no. 4, pp. 501515, 2016.

[21] F.-K. Wang, "Variables sampling plan for resubmitted lots in a process with linear profiles," Quality and Reliability Engineering International, vol. 32, no. 3, pp. 1029-1040, 2016.

[22] K. Govindaraju and S. Ganesalingam, "Sampling inspection for resubmitted lots," Communications in Statistics B: Simulation and Computation, vol. 26, no. 3, pp. 1163-1176, 1997.

[23] S. Balamurali and C.-H. Jun, "Repetitive group sampling procedure for variables inspection," Journal of Applied Statistics, vol. 33, no. 3, pp. 327-338, 2006.

[24] C.-W. Wu, M. Aslam, J. C. Chen, and C.-H. Jun, "A repetitive group sampling plan by variables inspection for product acceptance determination," European Journal of Industrial Engineering, vol. 9, no. 3, pp. 308-326, 2015. 
[25] C.-W. Wu, T.-H. Wu, and T. Chen, "Developing a variables repetitive group sampling scheme by considering process yield and quality loss," International Journal of Production Research, vol. 53, no. 7, pp. 2239-2251, 2015.

[26] A. Yan and S. Liu, "Designing a repetitive group sampling plan for Weibull distributed processes," Mathematical Problems in Engineering, Article ID 5862071, Art. ID 5862071, 10 pages, 2016.

[27] S. Balamurali and C.-H. Jun, "Multiple dependent state sampling plans for lot acceptance based on measurement data," European Journal of Operational Research, vol. 180, no. 3, pp. 1221-1230, 2007.

[28] M. Aslam, F. Wang, N. Khan, and C. Jun, "A multiple dependent state repetitive sampling plan for linear profiles," Journal of the Operational Research Society.

[29] Y. Tamirat and F.-K. Wang, "Sampling Plan based on the Exponentially Weighted Moving Average Yield Index for Autocorrelation within Linear Profiles," Quality and Reliability Engineering International, vol. 32, no. 5, pp. 1757-1768, 2016.

[30] R Core Team, R: A language and environment for statistical computing, R Foundation for Statistical Computing, Vienna, Austria, 2016. 


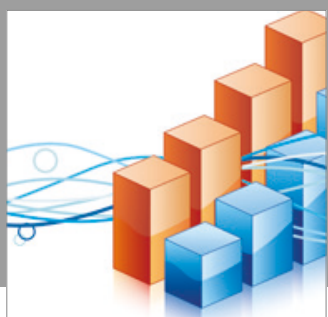

Advances in

Operations Research

vatersals

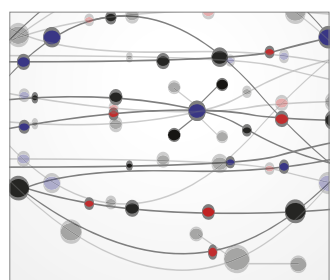

\section{The Scientific} World Journal
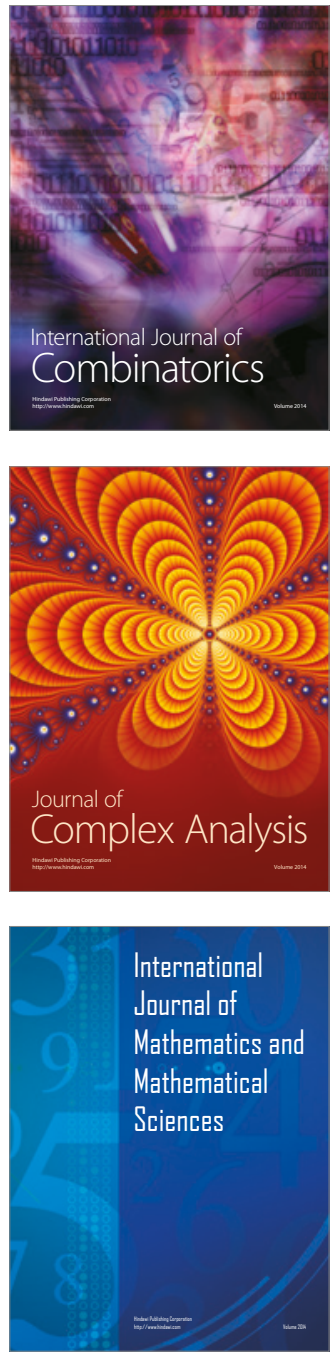
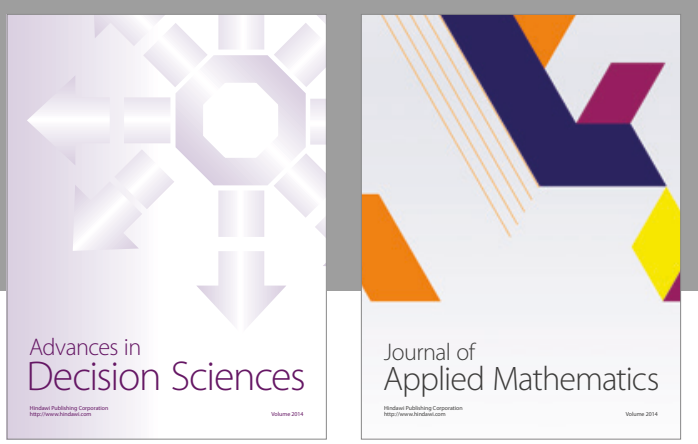

Algebra

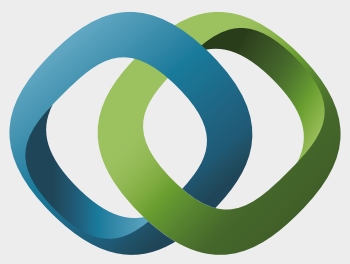

\section{Hindawi}

Submit your manuscripts at

https://www.hindawi.com
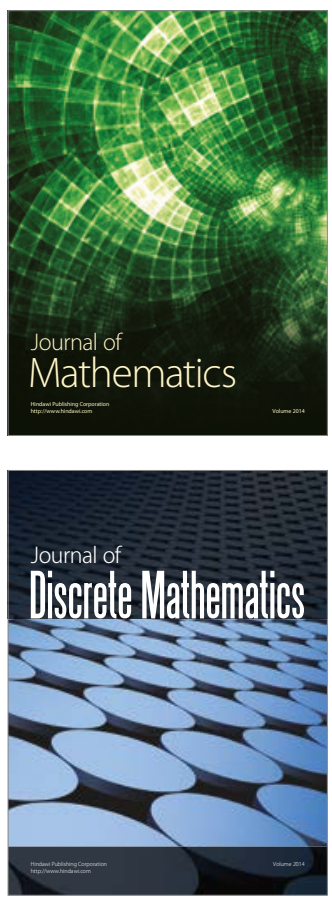

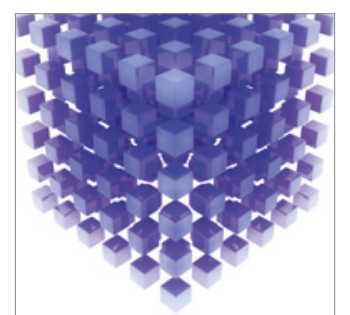

Mathematical Problems in Engineering
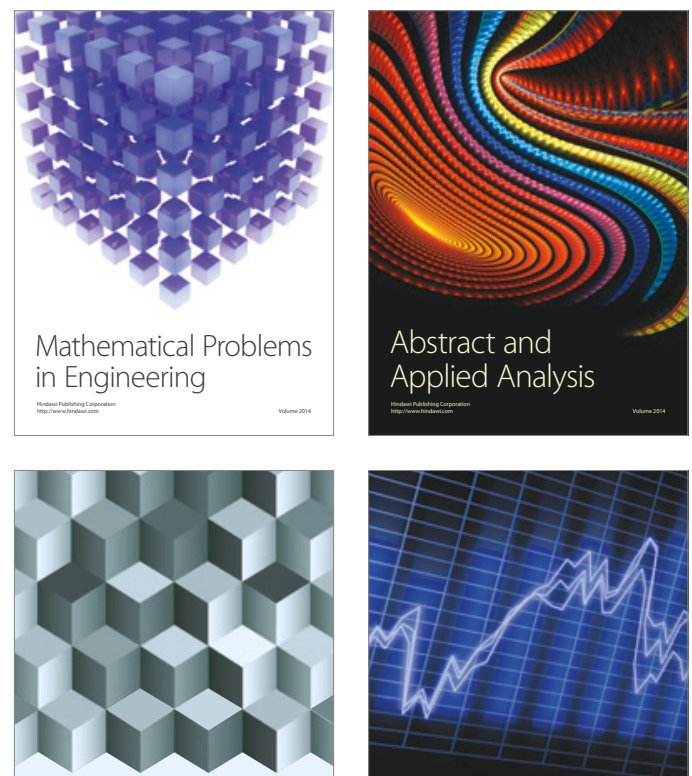

Journal of

Function Spaces

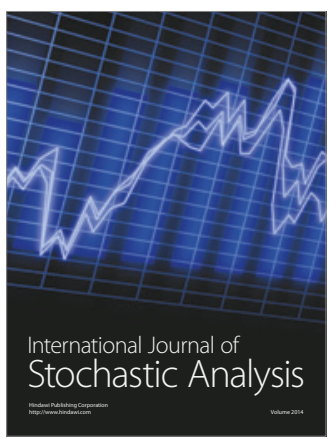

Probability and Statistics
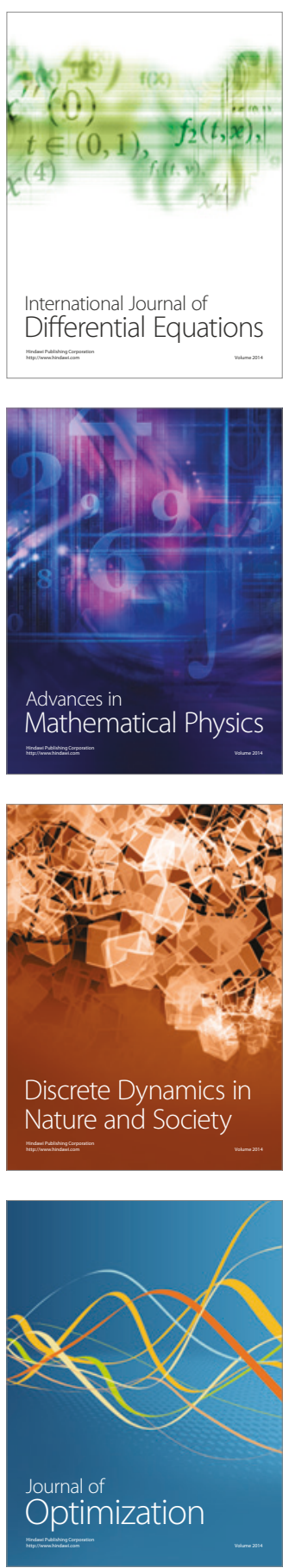